\title{
Germinação carpogênica de Sclerotinia sclerotiorum sob diferentes resíduos e extratos de plantas cultivadas
}

\author{
Francimar Perez Matheus da Silva ${ }^{1}$, Walber Luiz Gavassoni ${ }^{2}$, Lilian Maria Arruda Bacchi ${ }^{2}$, Fernanda Rodrigues Garcez ${ }^{3}$
}

${ }^{1}$ Bolsista CNPq, ${ }^{2}$ Prof. Associado, Laboratório de Fitopatologia, Faculdade de Ciências Agrárias, Universidade Federal da Grande Dourados, C. P. 533, CEP 79804-970, Dourados, MS. francimarms@gmail.com, walbergavassoni@ufgd.edu.br, lilianbacchi@ufgd.edu.br; 3 Prof. Associado, Departamento de Química, Universidade Federal de Mato Grosso do Sul, Campo Grande, MS, e-mail: fernanda.garcez@ufms.br. Parte da dissertação de mestrado da primeira autora.

Autor para correspondência: Walber Luiz Gavassoni (walbergavassoni@ufgd.edu.br)

Data de chegada: 18/02/2011. Aceito para publicação em: 03/06/2011.

1722

\section{RESUMO}

Silva, F.P.M.; Gavassoni, W.L.; Bacchi, L.M.A.; Garcez, F.R. Germinação carpogênica de Sclerotinia sclerotiorum sob diferentes resíduos e extratos de plantas cultivadas. Summa Phytopathologica, v.37, n.3, p.131-136, 2011.

Os efeitos de resíduos de plantas cultivadas e seus extratos sobre Sclerotinia sclerotiorum são poucos conhecidos. Três experimentos foram conduzidos, com resíduos de plantas cultivadas e seus extratos etanólicos e suas partições. Resíduos e extratos de culturas de aveia, ervilhaca, feijão, milheto, milho e trigo foram avaliados em condições controladas. Escleródios cobertos com resíduos de aveia, ervilhaca, feijão e milheto não germinaram carpogenicamente. Extratos etanólicos de resíduos de aveia e ervilhaca mostraram-se eficientes na inibição da germinação carpogênica, enquanto que do milheto e do trigo não diferiram da testemunha. Todas as partições de extratos etanólicos avaliadas reduziram a germinação carpogênica. Resíduos vegetais afetaram negativamente o número de apotécios emitidos por escleródio.

Palavras-chave adicionais: mofo-branco, extratos vegetais, apotécio, controle

\begin{abstract}
Silva, F.P.M.; Gavassoni, W.L.; Bacchi, L.M.A.; Garcez, F.R. Carpogenic germination of Sclerotinia sclerotiorum under crop residues and its extracts. Summa Phytopathologica, v.37, n.3, p.131-136, 2011.

The effects of crop residues and their extracts on Sclerotinia sclerotiorum are not well documented. Three experiments were conducted with crop residues and their ethanol and partition extracts. Oat, vetch, bean, pearl millet, corn and wheat were assessed under controlled conditions. Sclerotia covered with oat, vetch, bean and

pearl millet residues did not germinate carpogenically. Ethanol extracts of oat and vetch residues were efficient in inhibiting carpogenic germination whereas pearl millet and wheat did not differ from control. All partitioned ethanol extracts inhibited germination. Crop residues negatively affected the number of apothecia per sclerotium.
\end{abstract}

Keywords: White mold, plant extracts, apothecium, control.

O fungo Sclerotinia sclerotiorum (Lib.) de Bary é um patógeno cosmopolita e muito agressivo, podendo causar doenças em raízes, flores, vagens, sementes, hastes, madeira e frutos de diversas espécies vegetais (1). Segundo Boland \& Hall (2) mais de 400 espécies de plantas são relatadas como hospedeiras deste patógeno, incluindo monocotiledôneas e dicotiledôneas.

O controle do patógeno em diversas culturas tem sido difícil devido à formação de estruturas de repouso, que permitem sua sobrevivência por longos períodos. Os escleródios de $S$. sclerotiorum sobrevivem no solo por 6 a 8 anos (1). Os escleródios presentes no solo em condições favoráveis germinam e formam apotécios, que produzem grande quantidade de ascósporos, fonte primária de infecção.

Dentre as medidas de controle preventivas preconizadas para o mofo branco, em diversas culturas, destaca-se a adoção de um sistema de rotação de culturas com espécies não hospedeiras. O controle químico só é eficaz preventivamente e nem sempre viável economicamente (5).

O sistema plantio direto é uma alternativa para produção agrícola na região central do Brasil e caracteriza-se pelo cultivo em terreno coberto por palha, ausência de preparo de solo e adoção de sistemas de rotação de culturas (15). No entanto, os efeitos de resíduos culturais de plantas cultivadas sobre a viabilidade de estruturas de resistência de fungos fitopatogênicos, como S. sclerotiorum, são pouco conhecidos (16).

$\mathrm{Na}$ literatura há relatos de efeito de compostos produzidos por plantas como estimulantes da germinação de esporos de fungos, assim como estudos de atividade de extratos de plantas, óleos essenciais e metabólitos secundários isolados contra fungos fitopatogênicos, incluindo Sclerotium rolfsii (7) e $S$. 
sclerotiorum $(4,6,10,13,14,20,21,23,24,26)$.

O objetivo deste trabalho foi estudar a germinação carpogênica de S. sclerotiorum sob diferentes resíduos de plantas cultivadas e seus extratos.

\section{MATERIAL E MÉTODOS}

Foram conduzidos três experimentos para avaliar a germinação carpogênica de escleródios sob resíduos vegetais e seus extratos etanólicos e suas partições. O isolado do patógeno utilizado nos ensaios foi obtido em área naturalmente infestada da Fazenda Experimental de Ciências Agrárias (FAECA), da Universidade Federal da Grande Dourados (UFGD). Para a produção de escleródios, o patógeno foi repicado para erlenmeyers contendo uma camada de aproximadamente $20 \mathrm{~mm}$ de discos de cenoura previamente esterilizados. Após a repicagem, os frascos foram incubados a $25^{\circ} \mathrm{C}$, sob escuro pleno, por quatro semanas. Os escleródios formados foram armazenados à $5^{\circ} \mathrm{C}$ até o momento da instalação dos experimentos.

\section{Resíduos de plantas cultivadas}

Os resíduos culturais de aveia (Avena sativa L.), ervilhaca (Vicia sativa L.), feijão (Phaseolus vulgaris L.), milheto (Pennisetum glaucum (L.) R. Brown), milho (Zea mays L.) e trigo (Triticum aestivum L.) foram coletados nas áreas experimentais da FAECA/UFGD. Estes foram desidratados a $55^{\circ} \mathrm{C} / 48 \mathrm{~h}$ em estufa com circulação forçada de ar. Após a moagem em moinho de facas tipo Willye Tecnal modelo TE-340, os resíduos foram armazenados em freezer à $-30^{\circ} \mathrm{C}$. Neste ensaio, além dos resíduos foram inseridos dois tratamentos: cobertura com solo e testemunha ágar-água.

Após solidificação do meio ágar-água, 20 escleródios foram distribuídos eqüidistantes em cada gerbox. Os escleródios do tratamento testemunha foram cobertos com uma camada de dois mm de ágar-água, para evitar rolamento acidental. Aqueles dos tratamentos com resíduos culturais e com solo foram cobertos com camada de quatro $\mathrm{mm}$ do tratamento correspondente. O solo utilizado (Latossolo vermelhodistroférrico) foi coletado na área experimental da FAECA, seco ao ar, peneirado e esterilizado com brometo de metila, em contêiner lacrado (100 $\mathrm{cc} \mathrm{m}^{3}$ solo).

\section{Extratos de resíduos de plantas cultivadas}

Parte dos resíduos foi processada para a extração com etanol a frio. Os extratos obtidos foram concentrados sob pressão reduzida até atingirem consistência pastosa, e doravante denominados extratos etanólicos. O experimento constou de sete tratamentos (seis extratos e testemunha ágar-água). Os extratos foram dissolvidos em tubos de ensaio, com água esterilizada, na proporção de $0,5 \mathrm{~g}$ de extrato e 9,5 $\mathrm{mL}$ de água. Para melhor dissolução, os tubos foram colocados em banho-maria durante $20 \mathrm{~min} / 53^{\circ} \mathrm{C}$, e posteriormente, agitados em agitador Vortex até a dissolução do extrato. Os extratos vegetais, acrescidos de $490 \mathrm{~mL}$ de solução fundente e resfriada de ágar $(17 \mathrm{~g}$ ágar, $1000 \mathrm{ml}$ água) foram transferidos para gerbox $(11,5 \times 11,5 \times 3,5$ $\mathrm{cm}$ ), formando uma camada de aproximadamente $4 \mathrm{~mm}$. A concentração final dos extratos etanólicos foi de $1000 \mathrm{ppm}$. Em cada gerbox foram distribuídos 20 escleródios equidistantes. Os gerboxes foram incubados a $18^{\circ} \mathrm{C}$ e fotoperíodo de 12 horas luz/12 horas escuro.

\section{Partições de extratos de resíduos de plantas cultivadas}

As partições da fase hexânica, diclorometano, acetato de etila e hidrometanólica dos extratos etanólicos foram fornecidas pelo
Departamento de Química da UFMS. O experimento constou de 13 tratamentos: 12 fases provenientes da partição com solventes dos extratos etanólicos de resíduos culturais e testemunha ágar-água. Os procedimentos adotados na instalação e condução do experimento foram os mesmos descritos para o experimento com extratos etanólicos, exceto que a concentração final foi de 100 ppm.

\section{Delineamento experimental, avaliação e análise de dados}

Nos experimentos conduzidos neste estudo foi utilizado o delineamento inteiramente casualizado, com cinco repetições e o número de tratamento variando para cada ensaio. Cada unidade experimental foi constituída por um gerbox contendo 20 escleródios. As avaliações tiveram início a partir da verificação de formação de apotécios no tratamento testemunha. No experimento com resíduos de plantas cultivadas, após a primeira avaliação procedeu-se a remoção dos resíduos e do solo. Foram enumerados o número total de apotécios por unidade experimental e escleródios com formação de apotécios. Calculou-se então a quantidade de apotécios formados por escleródio e a germinação carpogênica $(\%)$.

As avaliações foram encerradas quando a germinação dos escleródios estabilizou-se. Ao final das avaliações, nos ensaios em que houve a supressão da germinação carpogênica, os escleródios não germinados foram lavados por três vezes em água esterilizada e transferidos para gerbox contendo ágar-água e novamente incubados, para verificar o efeito fungistático ou fungicida da inibição.

O aplicativo computacional SAS foi utilizado na análise estatística. Os dados de germinação carpogênica (\%) foram transformados em arco seno da raiz quadrada de $\mathrm{x} / 100$, e os demais em raiz quadrada de x, para análise de variância e teste de média LSD de Fischer.

\section{RESULTADOS E DISCUSSÃO}

Observou-se a emissão de estipes e formação de apotécios em escleródios dos tratamentos testemunha ágar-água e solo aos 45 dias após a instalação (DAI) do experimento. Cinco dias depois procedeuse a primeira avaliação e remoção da camada de resíduo e de solo. Restos culturais de aveia, ervilhaca, feijão e milheto suprimiram a formação de apotécios em todas as avaliações (Figura 1).

A germinação carpogênica nos escleródios do tratamento com resíduos de milho e trigo só foi observada a partir dos 65 DAI. Provavelmente devido à remoção da camada que formava uma barreira física, exercendo pressão mecânica nos escleródios. Outro fato que pode ter contribuído para esse comportamento foi a incidência de luz nos escleródios após a remoção da cobertura. Escleródios submetidos à alta intensidade luminosa desenvolvem apotécios em poucos dias e várias semanas são necessárias para a germinação carpogênica sob baixa luminosidade (25). Ferraz et al. (11), discutindo a menor incidência da doença causada por $S$. sclerotiorum em feijoeiro cultivado em sistema de plantio direto em relação ao convencional, apontaram a possibilidade da atuação da palhada como uma barreira física à emergência de estipes e ou a disseminação dos ascósporos. A supressão da germinação carpogênica foi mantida nos demais tratamentos, mesmo após a remoção dos resíduos, indicando que, além da barreira física, outros fatores poderiam estar envolvidos. As maiores porcentagens de germinação carpogênica ocorreram na cobertura com solo, provavelmente, porque sua estrutura favoreceu o arejamento e presença de luz para os escleródios, essenciais para a produção de apotécios (22).

Os escleródios provenientes do tratamento com ervilhaca 


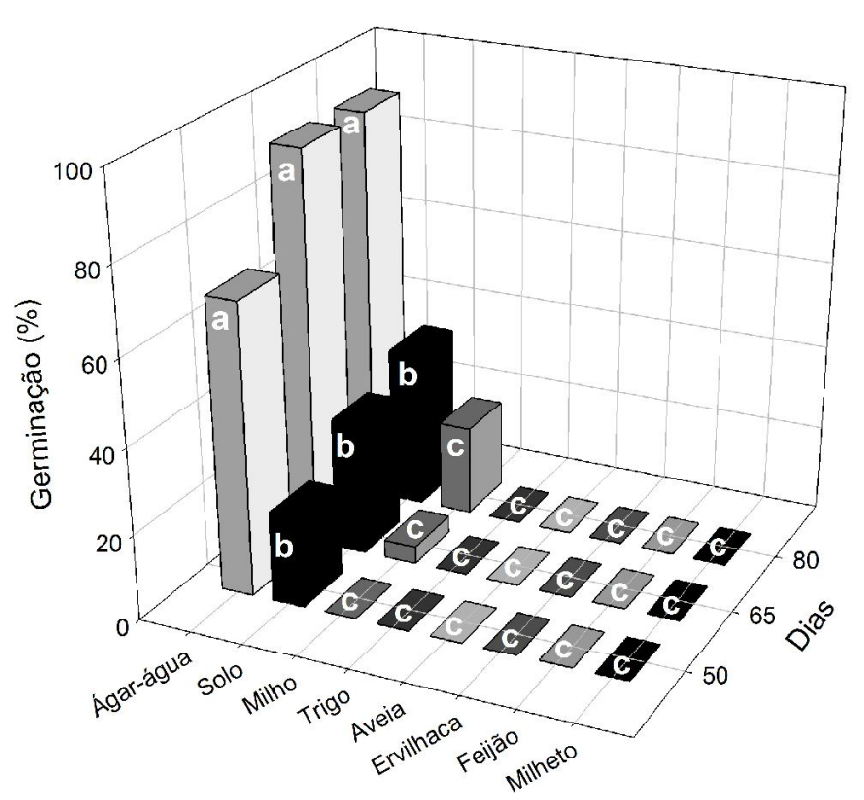

Figura 1. Germinação carpogênica de escleródios de Sclerotinia sclerotiorum sob efeito de diferentes resíduos de plantas cultivadas sobre os escleródios em camada de $\pm 4 \mathrm{~mm}$ com remoção aos 50 dias após a instalação (DAI) e posteriores avaliações aos 65 e 80 DAI.

Os dados foram transformados em arco seno raiz quadrada de $\mathrm{x} / 100$ para análise estatística. Médias seguidas pela mesma letra, em cada época de avaliação, não diferem significativamente entre si, segundo teste de LSD de Fischer $(\alpha=0,05)$.

apresentavam-se deteriorados devido à ação microbiana. Contaminantes, principalmente de natureza fúngica (Penicillium spp., Fusarium spp. e Aspergillus spp.) foram isolados de escleródios dos tratamentos com resíduos de ervilhaca, feijão e milheto. Ferraz et al. (10), estudando a viabilidade de $S$. sclerotiorum após solarização do solo, na presença de cobertura morta, encontraram maior eficiência na inativação do patógeno quando maior incidência e variabilidade de contaminantes foram encontradas. Steadman (24) destaca os gêneros Trichoderma e Penicillium dentre os fungos que produzem substâncias inibidoras e metabólitos antifúngicos. De maneira geral, entre os efeitos provocados pelas substâncias inibidoras, pode ser observada a redução ou paralisação do crescimento e esporulação, redução na germinação de esporos, além de distorções na hifa e endólise (4).

Aos 80 DAI, a germinação carpogênica na presença de resíduos de milho e trigo teve aumento considerável, embora inferior aos tratamentos testemunha e cobertura com solo. Melo et al. (19) também estudaram o efeito de resíduos culturais sobre $S$. sclerotiorum e encontraram maior porcentagem de germinação carpogênica com cobertura de milho, aveia+ervilhaca peluda+nabo e em restos culturais de um sistema envolvendo a cultura do trigo.

Após a remoção dos resíduos de aveia observou-se germinação miceliogênica dos escleródios.

Não houve germinação carpogênica dos escleródios cobertos com resíduos de feijão, milheto, ervilhaca e aveia. Resultado semelhante foi encontrado, em campo, por Lobo Júnior et al. (18), que relatam ausência ou número reduzido de apotécios, em áreas com plantio de gramíneas. Costa (8) também detectou efeito da palhada de Brachiaria brizantha Hochst Stapf na redução no número de escleródios (inóculo inicial) em ensaios a campo. O efeito da palhada de milheto na redução de inóculo inicial também foi observado.

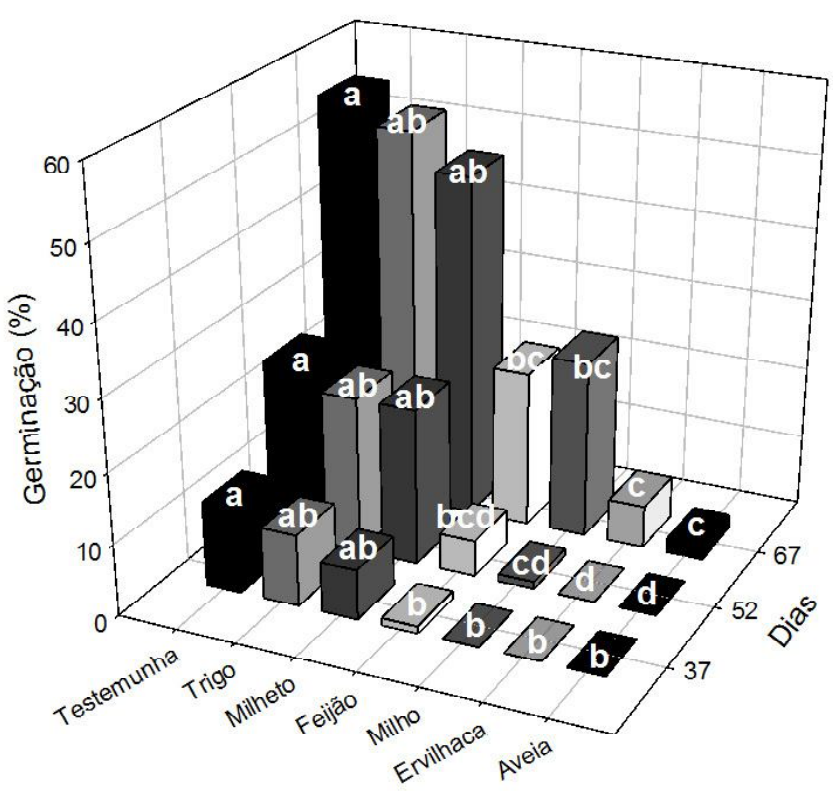

Figura 2. Germinação carpogênica de escleródios de Sclerotinia sclerotiorum sob efeito de diferentes extratos etanólicos obtido de resíduos de plantas cultivadas aos 37, 52 e 67 dias após a instalação.

Os dados foram transformados em arco seno raiz quadrada de $\mathrm{x} / 100$ para análise estatística.Médias seguidas pela mesma letra, em cada época de avaliação, não diferem significativamente entre si, segundo teste de LSD de Fischer $(a=0,05)$.

Aos 37 DAI procedeu-se a primeira avaliação no experimento com extratos etanólicos de resíduos (EER). Nesta avaliação, a germinação carpogênica não diferiu entre os tratamentos testemunha, trigo e milheto (Figura 2). Extratos de aveia, ervilhaca, feijão e milho reduziram a proporção de escleródios com apotécios. Aos 52 DAI, os escleródios tratados com extratos de resíduos de milheto e trigo tiveram germinação carpogênica igual à testemunha.

Os EER de aveia, ervilhaca, feijão e milho inibiram a germinação carpogênica dos escleródios em todas as épocas de avaliação quando comparado com a testemunha. Sharma \& Kapoor (23) detectaram efeito supressivo sobre a formação de apotécios por extratos aquosos de cambará (Gochnatia polymorpha (Less.) Cabrera) e da erva aromática Saussurea lappa ((Decne.) C.B.Clarke.).

Embora não tenha havido diferenças estatísticas na avaliação inicial entre os tratamentos com extrato de aveia e de ervilhaca e os demais resíduos, a ausência de germinação carpogênica evidencia seu efeito inibidor. Resultados semelhantes foram encontrados por Gavassoni et al. (12), onde o efeito supressor na formação de apotécios em escleródios de $S$. sclerotiorum foi observado em tratamentos com extratos de aveia, feijão, ervilhaca e trigo.

Os EER de milheto e trigo tiveram nas três avaliações realizadas, germinação carpogênica igual à testemunha. Apenas extratos de aveia e ervilhaca, apresentaram, em todas as épocas de avaliação, efeito significativo na redução da germinação carpogênica.

O número de apotécios formados por escleródio, tanto no experimento com resíduos de plantas cultivadas quanto no de extratos etanólicos são apresentados no Quadro 1. Todos os resíduos afetaram negativamente a formação de apotécios se comparados a testemunha agar-água. Os resíduos de aveia, ervilhaca, feijão e milheto suprimiram totalmente a germinação carpogênica. Aos 80 DAI, o número de 
apotécios formados por escleródio foi maior quando expostos ao resíduo de milho que nos outros resíduos, exceto o de trigo. Em relação ao número de apotécios formados, na primeira avaliação apenas os escleródios oriundos do tratamento com cobertura de solo e tratamento testemunha formaram apotécios. Resultados semelhantes foram obtidos por Ferraz et al. (9), que demonstraram ser possível reduzir a emissão de apotécios com a cobertura do solo com palha. Gracia-Garza \& Boland (13) também já relataram a redução do número de apotécios em áreas sob plantio direto, cuja camada de palha picada de milho ou trigo foi mantida sobre o solo. Ferraz et al. (10) encontraram menor número de apotécios, incidência e severidade de $S$. sclerotiorum em tratamentos com palha de Amaranthus sp. e nim (Azadirachta indica A. Juss).
Aos 52 DAI foi evidenciado o efeito dos EER de aveia e ervilhaca na supressão da formação de apotécios, embora Huang et al. (17) não tenham detectado efeito algum de extrato aquoso de aveia. Na última avaliação (67 DAI), os escleródios dos tratamentos com extratos de milho, trigo, feijão e milheto tiveram números de apotécios formados por escleródios iguais à testemunha. Um apotécio pode produzir até $2 \times 10^{8}$ ascósporos durante algumas semanas (3). A redução de aproximadamente $90 \%$ no número de apotécios pelos EER de aveia e ervilhaca em relação ao milho implica na redução do inóculo inicial de $S$. sclerotiorum. Costa (8) mostrou que a redução do inóculo inicial permitiu a redução no número de pulverizações e maior eficiência no controle da doença em feijão. Segundo o mesmo autor, em solos contendo diferentes densidades de inóculo

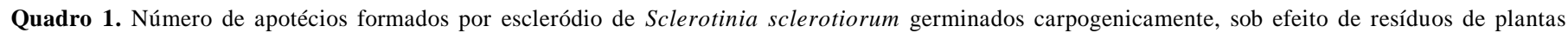
cultivadas e seus extratos etanólicos em diferentes épocas de avaliação.

\section{Apotécios por escleródio}

\begin{tabular}{|c|c|c|c|c|c|c|c|c|c|c|c|c|}
\hline \multirow{3}{*}{$\begin{array}{l}\text { Tratamento } \\
\text { Testemunha }\end{array}$} & \multicolumn{6}{|c|}{ Resíduo } & \multicolumn{6}{|c|}{ Extrato Etanólico } \\
\hline & \multicolumn{2}{|c|}{50} & \multicolumn{2}{|c|}{65} & \multicolumn{2}{|c|}{80} & \multicolumn{2}{|c|}{37} & \multicolumn{2}{|c|}{52} & \multicolumn{2}{|c|}{67} \\
\hline & 5,0 & a & 16,6 & $\mathrm{a}$ & 8,2 & $\mathrm{a}$ & 2,0 & $\mathrm{a}$ & 3,4 & $\mathrm{a}$ & 3,8 & $a b$ \\
\hline Milho & 0,0 & $\mathrm{c}$ & 0,7 & $\mathrm{bc}$ & 4,3 & $\mathrm{~b}$ & 0,0 & a & 0,8 & $\mathrm{ab}$ & 7,0 & $\mathrm{a}$ \\
\hline Trigo & 0,0 & $\mathrm{c}$ & 0,2 & $\mathrm{c}$ & 2,3 & $\mathrm{bc}$ & 1,6 & a & 2,9 & $\mathrm{ab}$ & 4,8 & $a b$ \\
\hline Feijão & 0,0 & $\mathrm{c}$ & 0,0 & $\mathrm{c}$ & 0,0 & $\mathrm{c}$ & 0,8 & $\mathrm{a}$ & 1,3 & $\mathrm{ab}$ & 4,3 & $\mathrm{ab}$ \\
\hline Milheto & 0,0 & $\mathrm{c}$ & 0,0 & $\mathrm{c}$ & 0,0 & $\mathrm{c}$ & 1,1 & $\mathrm{a}$ & 2,2 & $\mathrm{ab}$ & 4,7 & $\mathrm{ab}$ \\
\hline C.V. $(\%)$ & \multicolumn{2}{|c|}{28,5} & \multicolumn{2}{|c|}{44,8} & \multicolumn{2}{|c|}{33,8} & \multicolumn{2}{|c|}{43,1} & \multicolumn{2}{|c|}{47,6} & \multicolumn{2}{|c|}{44,3} \\
\hline
\end{tabular}

'na =não aplicável.

Os dados foram transformados em raiz quadrada de $\mathrm{x}$ para análise estatística.

Médias seguidas pela mesma letra na coluna não diferem significativamente entre si, segundo teste de LSD de Fischer $(\alpha=0,05)$.

Quadro 2. Germinação carpogênica de escleródios de Sclerotinia sclerotiorum sob efeito de extratos de resíduos de plantas cultivadas, com diferentes tipos de partições, aos 50,57, 64, 73 e 81 dias após a instalação do ensaio.

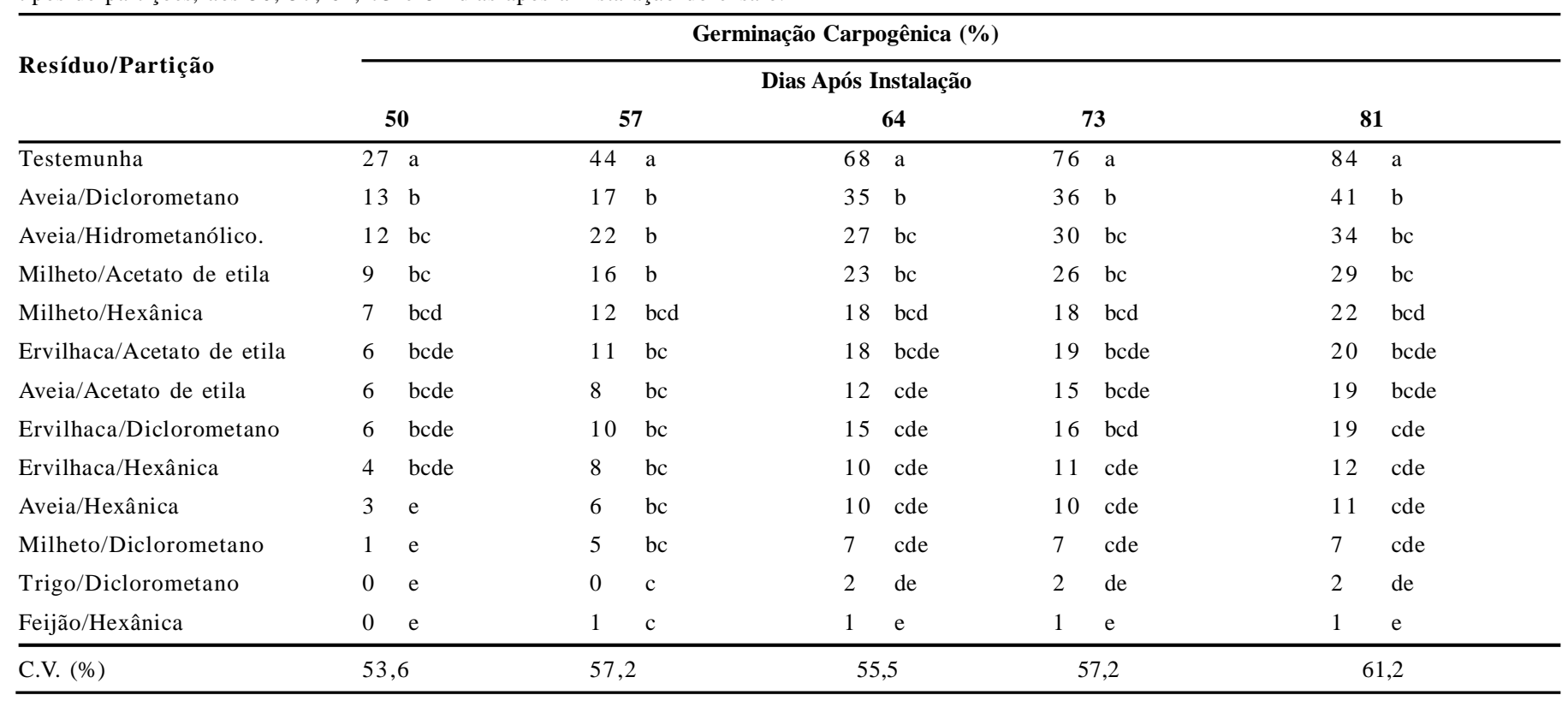

Os dados foram transformados em arco seno raiz quadrada de $\mathrm{x} / 100$ para análise estatística.

Médias seguidas pela mesma letra na coluna não diferem significativamente entre si, segundo teste de LSD de Fischer $(\alpha=0,05)$. 
(escleródios) no solo, o controle adequado da doença só foi obtido nas áreas com menos de 19 escleródios por $\mathrm{m}^{2}$ de solo. Em áreas com mais de 27 escleródios por $\mathrm{m}^{2}$, os fungicidas não foram eficientes no controle da doença. Obviamente estudos adicionais a campo, precisam confirmar o efeito dos resíduos de ervilhaca e aveia detectados em ensaios laboratoriais.

A supressão da germinação carpogênica, independente se por resíduos ou extratos/partições, apresentou-se permanente, ou seja, de caráter fungicida.

No experimento com as fases obtidas da partição dos extratos etanólicos de resíduos de plantas cultivadas, todas reduziram a germinação carpogênica em todas a as avaliações (Quadro 2), independente da fase de partição e do resíduo do qual foi extraído. Assim como no ensaio com extratos etanólicos, as fases obtidas da partição do extrato etanólico do resíduo de aveia, tais como a aveia acetato de etila, aveia diclorometano, aveia hexânica e aveia metanolágua e as de ervilhaca foram eficientes em reduzir a germinação carpogênica dos escleródios em todas as épocas de avaliação. A fase hexânica obtida do EER de feijoeiro promoveu redução de $97,6 \%$ na germinação carpogênica.

Embora não tenham sido estudadas características morfológicas tais como coloração e dimensões dos apotécios formados, foi observado que apotécios expostos aos extratos de resíduos e suas partições se apresentavam mal formados e com deterioração precoce.

Em condições controladas extratos etanólicos de feijão, milho, ervilhaca e aveia reduziram a germinação carpogênica. Todas as partições dos extratos etanólicos também influenciaram negativamente a germinação carpogênica. A cobertura com resíduos de aveia, ervilhaca, feijão e milheto suprimiu a germinação carpogênica.

A identificação do efeito estimulante e inibitório de resíduos vegetais e seus extratos abrem novas perspectivas para o manejo do mofo branco. Estudos com a aplicação dos compostos no solo em condições controladas e a campo são necessários.

\section{AGRADECIMENTOS}

À Fundação de Apoio ao Desenvolvimento do Ensino, Ciência e Tecnologia do Estado de Mato Grosso do Sul (FUNDECT/MS) pelos recursos financeiros e ao $\mathrm{CNPq}$ pela bolsa de mestrado concedida à primeira autora.

\section{REFERÊNCIAS BIBLIOGRÁFICAS}

1. Bianchini, A.; Maringoni, A.C.; Carneiro, S.M.T.P.G. Doenças do feijoeiro. In: Kimati, H.; Amorim, L.; Rezende, J.A.M.; Bergamin Filho, A.; Camargo, L.E.A. Manual de fitopatologia: doenças das plantas cultivadas. 4. ed. São Paulo: Agronômica Ceres, 2005. v.2, cap. 37 , p. 333-349.

2. Boland, G.J.; Hall, R. Index of plant hosts of Sclerotinia sclerotiorum. Canadian Journal Plant Pathology, Guelph, v. 16, n. 2, p. 93-108, 1994.

3. Bolton, M.D.; Thomma, P.H.J.B.; Nelson, B.D. Sclerotinia sclerotiorum (Lib.) de Bary: biology and molecular traits of a cosmopolitan pathogen. Molecular Plant Pathology, Bristol, v. 7, n. 1, p. 1-16, 2006.

4. Campbell, R. Biological control of microbial plant pathogens. Sidney: C.U.P, 1989. $218 \mathrm{p}$.

5. Canteri, M.G.; Pria, M.D.; Silva, O.C. Principais doenças fúngicas do feijoeiro. Ponta Grossa: UEPG, 1999, 178p.

6. Carpinella, M.C.; Giorda, L.M.; Ferrayoli, C.G.; Palacios, S.M. Antifungal effects of different organic extracts from Metia azedarach $\mathrm{L}$. on phytopathogenic fungi and their isolated active components. Journal of Agricultural and Food Chemistry, Washington, v.51, p. 250-251, 2003.

7. Clark, C.A. Influence of volatiles from healthy and decaying sweet potato storage roots on sclerotial germination and hyphal growth of Sclerotinia rolfsii. Canadian Journal of Botany, Ottawa, v. 67, p. 53-57, 1989.

8. Costa, J.L.S. Influência da braquiária no manejo de doenças do feijoeiro com origem no solo. In: Kluthcouski, J.; Stone, L. F.; Aidar, H. (Ed.). Integração lavoura-pecuária. Santo Antônio de Goiás: Embrapa Arroz e Feijão, 2003. p. 523-538.

9. Ferraz, L.C.L.; Bergamin Filho, A.; Amorim, L.; Nasser, L. C. B. Efeito da cobertura morta sobre o solo no cultivo de feijoeiro na formação de apotécios de Sclerotinia sclerotiorum. Fitopatologia Brasileira, Brasília, DF, v. 26, supl., p. 338, 2001. (Resumo).

10. Ferraz, L.C.L., Bergamin Filho, A., Amorim, L.; Nasser, L.C.B. Viabilidade de Sclerotinia sclerotiorum após a solarização do solo na presença de cobertura morta. Fitopatologia Brasileira, Brasília, DF, v. 28, n. 1, p. 17-26, 2003.

11. Ferraz, L.C.L.; Café Filho, A.C.; Nasser, L.C.B.; Azevedo, J. Effects of soil moisture, organic matter and grass mulching on the carpogenic germination of sclerotia and infection of bean by Sclerotinia sclerotiorum. Plant Pathology, London, v. 48, p. 77-82, 1999.

12. Gavassoni, W.L.; Serra, A.P.; Bacchi, L.M.; Oliveira, M.; Carvalho, P.M. Influência de extratos vegetais de plantas cultivadas sobre a germinação carpogênica de Sclerotinia sclerotiorum. Fitopatologia Brasileira, Brasília, DF, v. 26, supl., p. 279, 2006. (Resumo).

13. Gracia-Garza, J.A.; Boland, G.J. Influence of crop rotation and reduced tillage on white mold of soybean caused by Sclerotinia sclerotiorum. Phytopathology, St. Paul, v. 88, S33. 1998. (Resumo).

14. Hassan Dar, G.H.; Ahangar, F.A.; Qazi, N.A. Efficacy of various botanicals against Sclerotinia sclerotiorum. Journal of Food Legumes, New Delhi, v.20, p.119-120, 2007.

15. Hernani, L.C.; Salton, J.C. Manejo e conservação de solos. Circular Técnica. EMBRAPA CPAO, Dourados, n. 5, 1997. p.39-67.

16. HUANG, H.C.; ERICKSON, R.S.; CHANG, C.; MOYER, J.R.; LARNEY, F.J.; HUANG, J.W. Organic soil amendments for control of apothecial production of Sclerotinia sclerotiorum. Plant Pathology Bulletin, Taipei, v.11, p.207-214, 2002.

17. Huang, H.C.; Erickson, R.S.; Moyer, J.R. Effect of crop extracts on carpogenic germination of sclerotia, germination of ascospores and lesion development of Sclerotinia sclerotiorum. Allelopathy Journal, Haryana, v.20, p.269-277, 2007.

18. Lobo Júnior, M.; Lopes. C.A; Silva, W.L.C. Efeito de seis anos de rotação de culturas sobre a intensidade da podridãode-esclerotínia em tomateiro para processamento industrial. Fitopatologia Brasileira, Brasília, DF, v.23, sup1., p. 253, 1998. (Resumo).

19. Melo, R.A.; Bacchi, L.M.A.; Gavassoni, W.L. Restos culturais e germinação carpogênica de escleródios de Sclerotinia sclerotiorum. Fitopatologia Brasileira, Brasília, DF, v. 29, supl., p.128, 2004. (Resumo).

20. Müller-Riebau, F.; Berger, B.; Yegen, O. Chemical composition and fungitoxic properties to phytopatogenic fungi of essential oils of selected aromatic plants growing wild in Turkey. Journal of Agricultural and Food Chemistry, Washington, DC, v. 43, p. 2262-2266, 1995.

21. Pitarokili, D.; Tzakou, O.; Loukis, A; Harvala, C. Volatile metabolites from Salvia fruticosa as antifungal agents in soilborne pathogens. Journal of Agricultural and Food Chemistry, Washington, DC, v. 51, p. 3294-3301, 2003.

22. Phillips, A.J.L. Carpogenic germination of sclerotia of Sclerotinia sclerotiorum: a review. Phytophylactica, Pretoria, v.19, p. 279 283, 1987. 
23. Sharma, C.L. ; Kapoor, A.S. In vitro evaluation of herbicides and plant extracts against Sclerotinia sclerotiorum causing white rot in pea. Plant Disease Research, Ludhiana, v.14, p.79$81,1999$.

24. Steadman, J.R. Control of plant diseases caused by Sclerotinia species. Phytopathology, St. Paul, v. 69, p. 904-907, 1979.
25. Sun, P.; Yang, X. B. Light, temperature, and moisture effects on apothecium production of Sclerotinia sclerotiorum. Plant Disease, St. Paul, v. 84, n. 12, p. 1287-1293, 2000.

26. Zambonelli, A.; Zechini D'Aurelio, A; Bianchi, A; Albasini, A. Effects of essential oils on phytopatogenic fungi in vitro. Journal of Phytopathology, Berlin, v. 144, p. 494-494, 1996. 